\title{
Modelagem das atividades em centro cirúrgico de hospitais para o desenvolvimento de um sistema de informação hospitalar
}

Antonio Artur de Souza
Doutorado em Management Science pela Universidade de Lancaster - RU
Professor da Universidade Federal de Minas Gerais - UFMG
Avenida Antônio Carlos, 6627. Pampulha. Belo Horizonte/MG. CEP: 31270-901

E-mail: artur@face.ufmg.br

Mariana Guerra

Mestrado em andamento em Ciências Contábeis pela Universidade Federal de Minas

Gerais - UFMG

Avenida Antônio Carlos, 6627. Pampulha. Belo Horizonte/MG. CEP: 31270-901

E-mail: mariguerra@face.ufmg.br

Thaisy Las-Casas Amorin Universidade Federal de Minas Gerais - UFMG Avenida Antônio Carlos, 6627. Pampulha. Belo Horizonte/MG. CEP: 31270-901

E-mail: thaisy16@hotmail.com

Cynthia Oliveira Lara

Graduação em Ciências Atuariais pela Universidade Federal de Minas Gerais - UFMG Avenida Antônio Carlos, 6627. Pampulha. Belo Horizonte/MG. CEP: 31270-901

E-mail:cynthiaolara@hotmail.com

Simone Letícia Raimundini Doutorado em andamento em Administração pela Universidade Federal do Rio Grande do Sul - UFRGS Avenida João Pessoa, 52. Centro. Porto Alegre/RS. CEP: 90046-901 E-mail: simone.raimundini@ufrgs.br

\section{RESUMO}

No atual contexto da gestão financeira e de custos em organizações hospitalares, os sistemas de informações (SI) utilizados para o controle e análise dos custos tem sido um dos principais entraves para o gerenciamento e a tomada de decisões. Isso porque esses sistemas normalmente não disponibilizam as informações necessárias ao suporte da tomada de decisões de custos. Sabe-se que para a implantação de sistemas de custeio em hospitais, tais como o Activity-Based Costing (ABC - Custeio Baseado em Atividades), faz-se necessário o conhecimento dos custos dos serviços prestados e, ainda, dispor de um SI que processe as informações adequadamente. Para isto é essencial que o SI seja bem delineado e represente os processos e a sequência das atividades desenvolvidas na organização. Diante disso, entende-se que a modelagem 
Modelagem das atividades em centro cirúrgico de hospitais para o desenvolvimento de um sistema de informação hospitalar Antonio Artur de Souza, Mariana Guerra, Thaisy Las-Casas Amorin, Cynthia Oliveira Lara, Simone Letícia

das atividades possibilita o desenvolvimento de um SI adequado aos seus propósitos, atenda as demandas peculiares de cada setor, e possibilita a implantação do sistema ABC. Assim, este estudo tem como objetivo modelar as atividades desenvolvidas no centro cirúrgico (CC) e que possa ser utilizada como base para o desenvolvimento de um SI das organizações hospitalares estudadas. Por meio de estudos de casos múltiplos, foram realizadas entrevistas, coleta de dados e análise documental em três hospitais privados da cidade de Belo Horizonte/MG. Como principal resultado tem-se a definição do modelo de atividades desenvolvidas no CC desses hospitais, o qual possibilita identificar e conhecer em profundidade o setor, bem como as atividades realizadas e os recursos consumidos, com enfoque no controle interno para geração de informações de custos para tomada de decisões. A partir da modelagem apresentada, espera-se viabilizar o desenvolvimento de um SI para implantação do sistema $A B C$ em organizações hospitalares com estruturas e procedimentos semelhantes aos apresentados.

Palavras-chave: Sistemas de Informações. Modelagem. Custeio Baseado em Atividades. Centro Cirúrgico.

\section{Modeling surgery ward activities in hospitals in order to develop an information system}

\section{ABSTRACT}

Given the current financial and cost management situation in hospital organizations, the information systems (IS) used to control and analyze costs have been a major hindrance in management and decision making. What happens is that the information needed for cost decision making is not generally available in those systems. We know that introducing costing systems in hospitals, such as Activity-Based Costing (ABC), makes it necessary to know the cost of services offered and also requires an IS capable of processing information adequately. It is then essential that the IS be well designed and represent the processes and the sequence of activities performed in the organization. The activity modeling should then allow the development of an IS adequate to its purposes, meet the particular needs of each sector, and allow the introduction of the ABC system. Therefore, the goal of this study is to create a model for the activities performed in surgical wards (SW), one that can be used as the basis for developing an IS of the hospital institutions studied. These multiple-case studies applied interviews, data collection and document analysis in three private hospitals in the city of Belo Horizonte, in the state of Minas Gerais (Brazil). The main result is the definition of the activity model in those hospital's SW, which helps identify and thoroughly understand the sector as well as the activities performed and the resources demanded, the focus being the internal control that will generate the cost information necessary for decision making. This model is expected to develop an IS that will work as the basis for an ABC 
Modelagem das atividades em centro cirúrgico de hospitais para o desenvolvimento de um sistema de informação hospitalar Antonio Artur de Souza, Mariana Guerra, Thaisy Las-Casas Amorin, Cynthia Oliveira Lara, Simone Letícia Raimundini

system in hospital institutions with structures and procedures similar to those presented herein.

Key Words: Information Systems. Modeling. Activity Based Costing. Surgical Ward.

\section{INTRODUÇÃO}

Atualmente as organizações prestadoras de serviços de saúde apresentam problemas relacionados com dificuldades financeiras e má qualidade de serviços, indicando a ocorrência de uma ineficiente gestão hospitalar. A fim de minimizar os problemas enfrentados, de acordo com Malagón-Londoño et al. (2003), é necessário que os gestores dos hospitais definam e reordenem as atividades para a prestação de serviços de saúde. Por meio dessas medidas, os hospitais poderiam se adaptar ao ambiente de exigência de eficiência e de qualidade em que estão inseridos. Sob essa perspectiva, as organizações hospitalares têm atualmente um desafio de integrar a estrutura clínica de prestação dos serviços em saúde à estrutura administrativa de gestão das atividades operacionais. Para tanto, os responsáveis pela gestão financeira e de custos devem procurar atender às demandas do corpo clínico na atenção aos pacientes, de tal forma que essas demandas não comprometam a rentabilidade e a eficiência da organização como um todo. Afinal, normalmente, os hospitais que invertem tal relação, podem se tornar ineficientes operacional e financeiramente.

Por outro lado, segundo Alemi e Sullivan (2007), de forma geral, as organizações de saúde não conhecem os custos reais dos serviços prestados, o que prejudica a gestão financeira e a eficiência destas organizações. Abbas (2001) relata que grande parte dos hospitais não faz uso de um sistema de custos que oriente e ofereça parâmetros para as decisões financeiras e para o controle das atividades. Além disso, Raimundini (2003) e Struett (2005) assinalam que a ausência de um adequado sistema de informações (SI) contribui para o agravamento desta situação.

Nesse contexto caracterizado pela necessidade de melhorias na gestão financeira e de custos, bem como na qualidade dos serviços prestados, o presente estudo tem como objetivo apresentar a modelagem das atividades do Centro Cirúrgico 
Modelagem das atividades em centro cirúrgico de hospitais para o desenvolvimento de um sistema de informação hospitalar Antonio Artur de Souza, Mariana Guerra, Thaisy Las-Casas Amorin, Cynthia Oliveira Lara, Simone Letícia

(CC) de hospitais, que possa ser utilizada como base para o desenvolvimento de um SI adequado para essas organizações. Especificamente, pretende-se apresentar as condições para que o um SI possa ser desenvolvido especificamente para fornecer suporte à implantação do sistema Activity-Based Costing ( $A B C$ - custeio baseado em atividades) em tais organizações. A presente pesquisa foi realizada por meio de estudos de casos em três hospitais privados da cidade de Belo Horizonte/MG. A partir dos dados coletados nessas organizações, apresenta-se a modelagem das atividades do CC, a fim de possibilitar o desenvolvimento de um SI específico para hospitais.

Destaca-se, para tanto, que, de acordo com Furuie et al. (2007), os SI utilizados em hospitais devem fornecer informações imprescindíveis à eficiência e eficácia da gestão financeira e de custos, bem como, informações hospitalares sobre os procedimentos realizados para a prestação de serviços. Diante disso, os outputs dos SI devem evidenciar os resultados das atividades realizadas em organizações hospitalares, ou seja, "como" e "quanto" estas agregam valor aos serviços. Contudo, a adequabilidade dos outputs para essa avaliação depende da captura e do processamento dos dados, que, por sua vez, é dependente do framework desenvolvido na concepção do SI. Por isto, justifica-se que a modelagem das atividades é essencial para a elaboração do framework de qualquer $\mathrm{SI}$, uma vez que o modelo estabelecido se torna um parâmetro de atividade que será comumente capturada e monitorada por meio do SI.

Cumpre salientar que a delimitação da pesquisa em apenas um setor deve-se a complexidade dos hospitais como um todo, isto é, internamente há uma variabilidade e especificidades dos recursos consumidos, das atividades desenvolvidas, dos serviços prestados e dos profissionais especializados envolvidos (BOTELHO, 2006). Além disso, as atividades comumente desenvolvidas no $\mathrm{CC}$ podem se diferenciar de uma organização para outra.

Este artigo está dividido em seis seções, incluindo esta introdução. Nas seções 2 a 4, são abordadas as bases conceituais sobre o $C C$, o sistema $A B C$ em organizações hospitalares e modelagem de SI. A metodologia de pesquisa (estudos de casos múltiplos) é apresentada na seção 5. Especificamente, os resultados são analisados na 
Modelagem das atividades em centro cirúrgico de hospitais para o desenvolvimento de um sistema de informação hospitalar Antonio Artur de Souza, Mariana Guerra, Thaisy Las-Casas Amorin, Cynthia Oliveira Lara, Simone Letícia

seção 6 e referem-se à modelagem das atividades do CC. Já na seção 7, têm-se a conclusão e, por fim, as referências bibliográficas.

\section{REFERENCIAL TEÓRICO}

\subsection{Centro cirúrgico em organizações hospitalares}

O conjunto de elementos destinados às atividades cirúrgicas e à recuperação anestésica e pós-operatória é denominado CC (SILVA et al., 1997). De acordo com a Sociedade Brasileira de Enfermeiros de Centro Cirúrgico, Recuperação Anestésica e Centro de Materiais Esterilizados (SOBECC, 2008), o CC é uma das unidades mais complexas de um hospital. Essa complexidade decorre não somente de sua especificidade, mas também por se tratar de um setor no qual tanto o paciente quanto a equipe de profissionais de saúde envolvidos são expostos a situações de estresse. Por outro lado, além destes profissionais que compõem a equipe cirúrgica, atuam conjuntamente no CC profissionais responsáveis por serviços de apoio, como limpeza e higienização, e por atividades administrativas.

$\mathrm{Na}$ estrutura do hospital, o CC deve ter uma localização estratégica, ou seja, ocupar área independente da circulação geral, a fim de evitar o trânsito de pessoas e materiais estranhos ao serviço. Além disso, deve possibilitar o acesso livre e fácil de pacientes que são transportados deste setor para as Unidades de Internação, Pronto Socorro e Terapia Intensiva, bem como o encaminhamento dos pacientes às Unidades de origem (SILVA et al., 1997). Quanto à estrutura específica do setor, geralmente, o CC é composto de três áreas: irrestrita, semi-restrita e restrita. Na primeira, encontra-se a secretaria do CC, e na irrestrita localizam-se as salas de expurgo, as de preparação de materiais e medicamentos bem como uma sala de estar. Já na área restrita, têm-se as salas de cirurgia e de recuperação pós-anestésica, além de lavabos e depósito (HU UFSC, 2008).

Dada a sua estrutura, a fim de apresentar o processo de prestação de serviços comumente desenvolvido no CC, Botelho (2006) apresenta um exemplo de fluxograma deste setor (Figura 1), denominado pelo autor de Bloco Cirúrgico. 
Modelagem das atividades em centro cirúrgico de hospitais para o desenvolvimento de um sistema de informação hospitalar Antonio Artur de Souza, Mariana Guerra, Thaisy Las-Casas Amorin, Cynthia Oliveira Lara, Simone Letícia

Raimundini

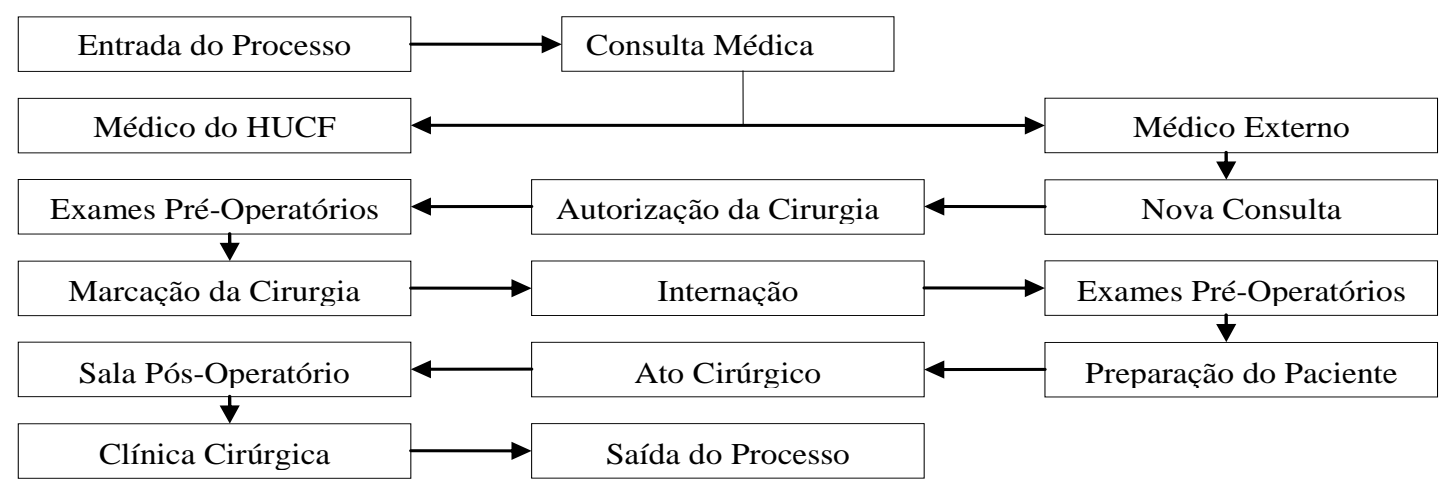

Figura 1: Fluxograma do Bloco Cirúrgico no Hospital Universitário Clemente Farias (HUCF). Fonte: Botelho (2006).

As informações sobre esse processo do CC incluem desde os dados de entrada do paciente, das consultas e exames realizados, até os dados de saída. As setas apresentadas no fluxograma mostram a seqüência das atividades e dos setores nos quais o paciente do CC está submetido.

Apesar do CC apresentar a estrutura específica para a execução de diversos tipos de cirurgias, destaca-se que algumas dessas podem ser realizadas no ambulatório, conforme as características do procedimento e com o nível do risco de morte envolvido. Os procedimentos cirúrgicos realizados no ambulatório, ocorrem no denominado "Hospital Dia". A Figura 2 mostra o fluxograma do paciente neste tipo de cirurgia que é, normalmente, de urgência e/ou de emergência.

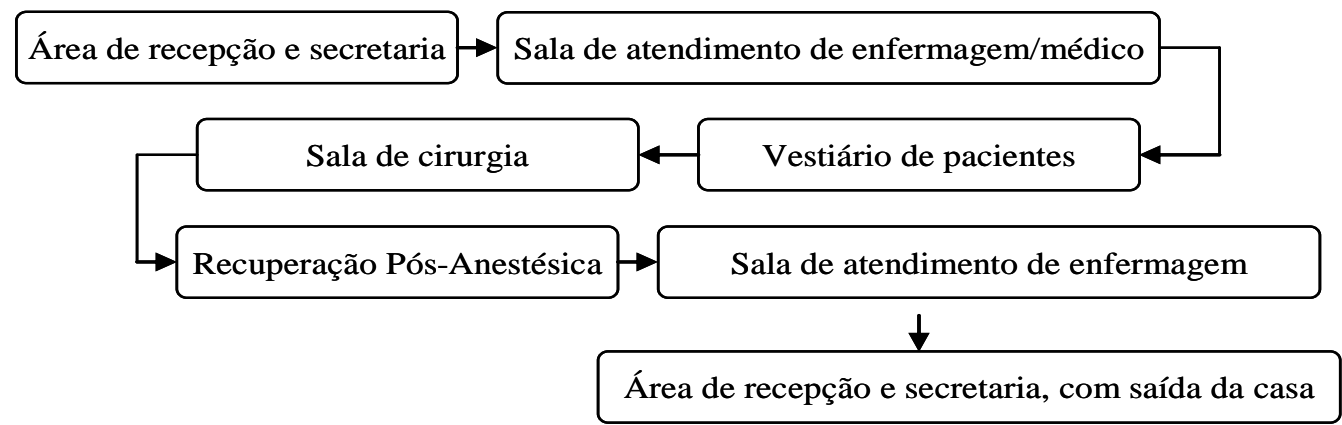

Figura 2. Fluxograma do paciente na cirurgia ambulatorial

Fonte: Silva et al. (1997). 
Modelagem das atividades em centro cirúrgico de hospitais para o desenvolvimento de um sistema de informação hospitalar Antonio Artur de Souza, Mariana Guerra, Thaisy Las-Casas Amorin, Cynthia Oliveira Lara, Simone Letícia

Os procedimentos do "Hospital Dia" são mais simples do que as etapas do CC descritas por Botelho (2006). A diferenciação das cirurgias realizadas no CC em relação ao ambulatório decorre do nível de complexidade, envolvendo maior ou menor tempo para execução, além da necessidade de maior quantidade de recursos físicos e profissionais. As Figuras 1 e 2 contemplam especificidades dos processos de prestação dos serviços, ou seja, a realização das cirurgias.

Dada a complexidade e especificidade dos processos, para que o CC funcione de forma eficiente, faz-se necessário ter conhecimento aprofundado sobre as diferentes atividades desenvolvidas no processo. Além disso, para a qualidade dos serviços, deve-se garantir um ambiente seguro aos pacientes e aos profissionais, conforme as normas de vigilância sanitária (SOBECC, 2009). Ghellere et al. (1993) destacam, ainda, a necessidade de incentivo à promoção de pesquisas, desenvolvimento e utilização de novas tecnologias, além da ampliação do conhecimento técnico-científico de tais profissionais. Entretanto, o conhecimento pormenorizado de todas as atividades envolvidas no processo de prestação de serviços pode implicar em custos altos para a organização hospitalar.

\subsection{Custeio baseado em atividades}

O sistema $A B C$ surgiu como uma alternativa para auxiliar a tomada de decisão em detrimento dos sistemas de custeio tradicionais. $O A B C$ é indicado como uma ferramenta superior aos demais sistemas, no que se refere à capacidade de gerar informações de suporte à decisão gerencial (BRIMSON, 1996; FINKLER; WARD, 1999; UPDA, 1996).

O pressuposto fundamental do sistema ABC, segundo Hansen e Mowen (2006), é uma alocação mais eficiente dos custos indiretos aos produtos ou serviços, utilizando como meio de mensuração as atividades, haja vista a premissa de que as atividades consomem recursos e os produtos ou serviços consomem as atividades. Além disso, consoante McLean (2003), o sistema ABC é voltado para atividades que possuem predominância de custos indiretos, com o objetivo de aprimorar a alocação desses custos. Esse diferencial possibilita que a organização evite distorções decorrentes de 
Modelagem das atividades em centro cirúrgico de hospitais para o desenvolvimento de um sistema de informação hospitalar Antonio Artur de Souza, Mariana Guerra, Thaisy Las-Casas Amorin, Cynthia Oliveira Lara, Simone Letícia Raimundini

subavaliação ou superavaliação dos custos aos produtos ou serviços, além de possibilitar o controle de sua causa (HORNGREN et al., 2004).

Especificamente, por meio do sistema $A B C$, verifica-se como os custos das atividades estão relacionados com a geração de receitas e com o consumo dos recursos, rastreando as atividades (CHING, 1997). Assim, é possível mensurar, por meio desse sistema, o valor que cada atividade acresce ao resultado da organização. Essa é a principal diferença do $A B C$ para os outros sistemas de custeio, que alocam os custos dos recursos diretamente ao produto ou serviço. Os hospitais, configurando-se como empresas prestadoras de serviços em saúde, podem se beneficiar com a implantação e a utilização do sistema $A B C$ para a gestão financeira e de custos.

Diversas pesquisas, como de Abbas (2001), Raimundini (2003) e Struett (2005), têm sido publicadas nos últimos anos a respeito da aplicabilidade e da utilização do sistema $A B C$ em hospitais para fins de gestão e de tomada de decisão. Para esses autores, o sistema $A B C$ apresenta-se, ainda, como uma ferramenta pouco utilizada para auxiliar os gestores no controle e na gestão das organizações de saúde. Possivelmente, um fator que justifica tal fato é a incipiente utilização de um SI adequado para gerar as informações que ofereçam suporte ao controle dos custos. Cardinaels et al. (2004) e Éden et al. (2006) reconhecem que o sistema ABC proporciona informações mais precisas e aperfeiçoa o uso dos recursos, além de possibilitar melhor controle das atividades desenvolvidas. Entretanto, estes mesmos autores confirmam que um dos principais motivos que levam os hospitais a não adotarem o sistema $A B C$ é a ineficiência dos SI utilizados nessas organizações no que tange às informações disponibilizadas para o suporte da tomada de decisão financeira e de custos.

Em um estudo de caso desenvolvido por Botelho (2006), o autor apresenta um modelo de utilização do sistema $A B C$ para o HUCF. Para tanto, identificou as atividades e os direcionadores para mensuração dos custos em todas as áreas desse hospital público. Apesar de propor um modelo, a pesquisa de Botelho (2006) não contemplou o desenvolvimento de um Sistema de Informações Hospitalar $(\mathrm{SIH})$ para a gestão de custos. Conforme Cardinaels et al. (2004), hospitais necessitam de SIH que 
Modelagem das atividades em centro cirúrgico de hospitais para o desenvolvimento de um sistema de informação hospitalar Antonio Artur de Souza, Mariana Guerra, Thaisy Las-Casas Amorin, Cynthia Oliveira Lara, Simone Letícia Raimundini

disponibilizem informações para a gestão e tomada de decisões, ou seja, sistemas específicos para hospitais que forneçam informações sobre os custos das atividades e dos serviços dos diferentes setores da organização.

Segundo Bittencourt (1999), a informação de custos, juntamente com a análise de processos e de valor agregado, torna o sistema $A B C$ uma importante ferramenta para a elaboração de indicadores de desempenho e, conseqüentemente, um instrumento gerencial para os gestores de saúde. Esse sistema pode contribuir para a melhoria da qualidade do atendimento, apoiar o desenvolvimento de protocolos de diagnóstico e tratamento e disponibilizar informações para que a organização negocie preços junto ao mercado e ao governo. Para tanto, um SIH para a área de saúde deve (i) proporcionar uma análise da eficiência dos serviços prestados, bem como indicar possíveis melhorias nos processos de prestação dos serviços; (ii) prover informações suficientes para a otimização dos recursos de pessoal e de infra-estrutura disponíveis; e (iii) auxiliar no contínuo incremento da qualidade.

Considerando a utilização de um adequado $\mathrm{SIH}$, bem como o envolvimento dos diferentes profissionais nos diversos serviços prestados pelo hospital, é possível apresentar um sistema e um modelo de atividades que possibilitem a implantação do $A B C$ nessas organizações.

\subsection{Modelagem para sistemas de informações}

Define-se modelagem como a simplificação de parte da realidade para algum propósito definido (BOOCH et al., 2005; PIDD, 1998). No contexto dos SI, a modelagem trata da representação externa e explícita dos "itens" que são "controlados" e "disponibilizados" pelo sistema, a fim de que o usuário entenda, planeje, gerencie e controle a realidade organizacional. No presente estudo, o foco é modelar as atividades desenvolvidas no setor CC para a prestação de serviços em três hospitais. Entende-se que a modelagem das atividades para o desenvolvimento e a utilização de um SIH possibilita uma melhor compreensão e integração do sistema e envolve a identificação de itens considerados importantes de acordo com cada perspectiva - nessa pesquisa, a perspectiva de gestão financeira e de custos. 
Modelagem das atividades em centro cirúrgico de hospitais para o desenvolvimento de um sistema de informação hospitalar Antonio Artur de Souza, Mariana Guerra, Thaisy Las-Casas Amorin, Cynthia Oliveira Lara, Simone Letícia Raimundini

Destaca-se que um modelo a ser utilizado para o desenvolvimento de um SI tem como objetivos: (a) testar determinado item antes de lhe dar a forma informatizada para corrigir falhas que poderiam ou estariam ocorrendo no output do sistema; (b) definir para os usuários uma parte ou o todo de um item e o seu comportamento; (c) visualizar, por meio do sistema, variáveis que seriam visíveis apenas na prática; e (d) reduzir a complexidade a partir da divisão de um item em partes (RUMBAUGH et al., 1994). Assim, ter-se-ia uma simplificação dos itens observáveis e tratáveis na realidade, a qual poderia auxiliar no controle e na avaliação desses itens.

Para Zanoteli (2001), a modelagem conceitual é essencial para os casos em que as situações reais são complexas, tanto por gerar representações simplificadas como por se configurar como instrumento de comunicação e entendimento entre as partes envolvidas. Assim, pode-se concluir que a modelagem é a primeira medida técnica de um projeto, possibilitando a preparação para as outras etapas, tais como administração e avaliação, que inclui a monitoração, a análise e o julgamento. No caso da modelagem das atividades para o desenvolvimento de um $\mathrm{SIH}$, tem-se que o modelo estará bem configurado quando a descrição das atividades, dos objetivos, do tempo, dos recursos requeridos e das condições de gestão puder ser monitorada, analisada e julgada de forma positiva ou negativa.

Pidd (1998) define alguns princípios de modelagem. Segundo o autor, é necessário que os modelos sejam simples para possibilitar o entendimento de forma rápida e fácil, porém devem ser suplementados por um pensamento crítico e argumentativo, além de uma análise minuciosa. É importante também que no processo de modelagem se inicie com os elementos bem definidos e óbvios do sistema de interesse e, à medida que esses sejam modelados e validados, sejam adicionados os elementos de menor definição e mais complexos. Posteriormente, é necessário que se decomponha o modelo maior e complexo em um conjunto de modelos mais simples, utilizando-se metáforas, analogias e similaridades. Isso possibilitaria insights sobre o funcionamento e a utilização do sistema. Modelar as atividades para fins de desenvolvimento de um $\mathrm{SIH}$, significa modelar o processo de ocorrência ou realização dos itens relacionados (p.e., os recursos, as atividades e serviços). O modelo, nesse 
Modelagem das atividades em centro cirúrgico de hospitais para o desenvolvimento de um sistema de informação hospitalar Antonio Artur de Souza, Mariana Guerra, Thaisy Las-Casas Amorin, Cynthia Oliveira Lara, Simone Letícia Raimundini

sentido, deve representar as seqüências de operações que ocorrem em resposta a estímulos externos (i.e., eventos), descrevendo o aspecto de fluxo de controle do sistema (RUMBAUGH et al., 1994).

A modelagem, portanto, consiste em um exercício que sistematiza os processos que o $\mathrm{SI}$ deve realizar para controle e monitoramento dos itens relacionados nesse (NERI; HOPPEN, 2003). A modelagem pode ser realizada a partir de diversos diagramas (p.e., casos de uso, interação, seqüência, fluxogramas). Os diagramas de atividades, por exemplo, são utilizados para modelar itens dinâmicos de um sistema, mostrando o fluxo de uma atividade para outra atividade em um sistema e pode ser empregado na modelagem do contexto de uma organização (LENZ; KUHN, 2004). Neri e Hoppen (2003) comentam que diagramas de atividades apresentam o fluxo de procedimentos necessários para atingir um determinado fim e Booch et al. (2005) definem atividade como uma execução em andamento resultante de alguma ação.

Zanoteli (2001) ressalta, entretanto, a existência de limites em um modelo, uma vez que este busca ser suficientemente detalhado para que possibilite obterem-se conclusões sobre a realidade. A limitação deve-se a possibilidade de não se alcançar um perfeito detalhamento. $O$ autor também ressalta que a utilização de outros modelos pode se fazer necessária sempre que se pretenda investigar mudanças. No presente estudo o sistema é o $\mathrm{SIH}$, sendo que a pesquisa se concentra no estudo da modelagem de atividades desenvolvidas no CC de três hospitais. Dessa forma, a referida modelagem consiste em estabelecer parâmetros (modelos) das atividades realizadas, bem como o relacionamento dessas como os recursos e os serviços, dado por meio dos direcionadores de custos e de recursos, dentro do contexto de aplicação do ABC.

\section{METODOLOGIA DE PESQUISA}

A presente pesquisa baseia-se em estudos de casos múltiplos realizados durante o período de 2006 a 2008 em três hospitais da cidade de Belo Horizonte/MG, denominados neste artigo de Hospital I, Hospital II e Hospital III. O estudo de caso é um método que contribui significativamente para a compreensão dos fenômenos 
Modelagem das atividades em centro cirúrgico de hospitais para o desenvolvimento de um sistema de informação hospitalar Antonio Artur de Souza, Mariana Guerra, Thaisy Las-Casas Amorin, Cynthia Oliveira Lara, Simone Letícia Raimundini

individuais, organizacionais, sociais e políticos complexos, por intermédio de uma investigação ex post facto de eventos da vida real e da geração de um perfil dos eventos pesquisados (YIN, 2005). Dentre os métodos de pesquisa, o estudo de caso é aquele mais recomendado e aplicado em pesquisas na área de ciências sociais aplicadas, quando da realização de um estudo em profundidade sobre determinado evento, com a possibilidade de comparação com outros estudos realizados, simultaneamente ou não (VAIVIO, 2008).

Denzin e Lincoln (2005) consideram que esse método alcança maior credibilidade quando se realiza a triangulação dos dados, seguida de sua interpretação. A triangulação é o processo que utiliza os diversos dados da pesquisa, levantados a partir de várias técnicas de coleta de dados, para a compreensão das variáveis pesquisadas. Esse processo contribui para a validação de um constructo, haja vista que várias fontes de evidências fornecem diversas constatações sobre o mesmo fenômeno em estudo (YIN, 2005).

Cumpre salientar que esta pesquisa não visou validar um constructo, e sim um modelo que sirva de estrutura básica para o desenvolvimento de um SIH em um tipo de organização. Especificamente, o modelo a ser validado refere-se às atividades desenvolvidas para a prestação dos serviços do CC de hospitais. Entende-se que esse modelo poderia possibilitar o desenvolvimento de um SIH que contemple o sistema ABC.

Além disso, destaca-se que esta pesquisa, de natureza qualitativa, enfatiza a busca e a verificação de teorias já existentes. Esse tipo de pesquisa visa a investigação de eventos com maior profundidade, por meio de entrevistas e observações in loco e da identificação de variáveis que se complementam, confirmam ou contrastam (DENZIN; LINCOLN; 2005). Para tanto, utilizou-se de técnicas de coleta de dados: observações diretas não-participantes, entrevistas não-estruturadas e semi-estruturadas e consulta a arquivos (dados financeiros e contábeis) e documentos das organizações pesquisadas. Ainda, o referencial teórico construído com base em livros, artigos, teses e materiais disponíveis em sítios, em especial no portal de periódicos da CAPES, contribuiu para fundamentar os resultados obtidos com os dados da pesquisa de campo. 
Modelagem das atividades em centro cirúrgico de hospitais para o desenvolvimento de um sistema de informação hospitalar Antonio Artur de Souza, Mariana Guerra, Thaisy Las-Casas Amorin, Cynthia Oliveira Lara, Simone Letícia

A realização de entrevistas não-estruturadas e semi-estruturadas fundamentouse no fato de que as primeiras possibilitam que o entrevistado fale do campo de pesquisa de modo amplo e pessoal, sem muitas intervenções do entrevistador (FLICK, 2004). Munido dessas informações, o entrevistador, por sua vez, pôde melhor executar a observação direta não-participante e a entrevista semi-estruturada. A entrevista semiestruturada possibilitou que o entrevistado respondesse às questões de interesse do pesquisador, a fim de confirmar ou complementar os dados obtidos na entrevista não estruturada e observação direta não-participante. Nessa entrevista, o entrevistado também pôde - limitado ao foco de pesquisa controlado pelo pesquisador - expor a sua opinião e descrever os eventos, além de ter acesso a alguns dos documentos utilizados pelos CC dos hospitais estudados.

A análise dos dados consistiu na utilização de técnicas específicas para a leitura das questões abertas tratadas nas entrevistas, com base na análise definida por Bardin (1977) e Cullinane e Toy (2000). Iniciou-se o trabalho com um estudo minucioso da transcrição da entrevista realizada com os gestores sobre o CC de cada hospital. Em seguida, foram construídas grades de leitura que possibilitaram a classificação das respostas em categorias e subcategorias, o que possibilitou a comparação dos três hospitais de forma direcionada, sistemática e categorizada. Além disso, um protocolo de pesquisa permitiu a melhor condução das atividades de coleta e análise de dados levantados. Segundo Yin (2005), o protocolo de pesquisa é um mecanismo útil e relevante para conduzir e aumentar a confiabilidade do estudo de caso. A finalidade desse tipo de protocolo é orientar os pesquisadores na condução do estudo, em especial das atividades de pesquisa de campo, principalmente quando da realização de estudos de casos múltiplos.

\section{RESULTADOS DA PESQUISA}

\subsection{Hospital I}

O Hospital I é um hospital-maternidade privado de natureza filantrópica. O CC desse Hospital divide-se em dois blocos (centros): cirúrgico e obstétrico. No bloco 
Modelagem das atividades em centro cirúrgico de hospitais para o desenvolvimento de um sistema de informação hospitalar Antonio Artur de Souza, Mariana Guerra, Thaisy Las-Casas Amorin, Cynthia Oliveira Lara, Simone Letícia Raimundini

cirúrgico são realizadas diariamente vasectomias, laqueaduras e cirurgias de varizes. Estas cirurgias, normalmente são previamente agendadas pela secretaria do setor, não havendo, portanto, cirurgias de emergência. Nesse bloco há oito leitos que funcionam diariamente, sendo que a rotatividade de pacientes é grande, uma vez que os pacientes submetidos às cirurgias recebem alta no mesmo dia, no caso das cirurgias ambulatoriais ("Hospital Dia").

Para o procedimento de vasectomia, os pacientes recebem alta hospitalar logo após a intervenção cirúrgica. As cirurgias de varizes são realizadas à tarde, e os pacientes recebem alta no período da noite. As laqueaduras são realizadas pela manhã, e as pacientes recebem alta ao meio-dia. De forma geral, são realizadas diariamente, em média, quinze vasectomias, oito cirurgias de varizes e de laqueaduras.

No bloco obstétrico, o plantão da equipe médica abrange um período de 12 horas, sendo realizados, diariamente, parto cesárea e parto normal. A média mensal destes procedimentos é de novecentos partos, sendo aproximadamente $80 \% \circ$ procedimento do parto normal. Esse bloco é composto por duas salas cirúrgicas com um leito em cada, onde ficam três médicos plantonistas. $O$ processo inicia-se com o atendimento da paciente no Pronto-Atendimento (PA). Se diagnosticado quadro clínico indicativo de parto cesárea, a paciente é encaminhada para uma enfermaria específica para aguardar o momento do procedimento, localizada em frente ao bloco obstétrico, o que é fundamental em caso de alguma complicação. Nesse local, a paciente aguarda 0 atendimento, que irá ocorrer no bloco obstétrico seguindo uma ordem de prioridade, e não de chegada. Ao final de cada cirurgia, a sala cirúrgica é higienizada e preparada para o próximo parto. Ressalta-se a possibilidade de haver plantões em que não é realizado parto cesárea, uma vez que o hospital incentiva a realização do parto normal.

Quando no PA são diagnosticadas condições para a execução de parto normal, a paciente é encaminhada para internação em um leito específico, que consiste em um box individual onde ela permanece no período pré-parto, sendo que neste mesmo local é realizada a cirurgia. Após o nascimento dos bebês, as pacientes são hospedadas na enfermaria. Caso haja alguma intercorrência, o parto não é realizado no leito, e sim na sala de parto do bloco obstétrico. 
Modelagem das atividades em centro cirúrgico de hospitais para o desenvolvimento de um sistema de informação hospitalar Antonio Artur de Souza, Mariana Guerra, Thaisy Las-Casas Amorin, Cynthia Oliveira Lara, Simone Letícia

Raimundini

Dada a descrição das atividades realizadas, a Figura 3 apresenta o diagrama das atividades relacionadas com os procedimentos de parto normal e cesárea. $O$ conceito de diagrama de atividades é baseado no modelo "caso de uso", utilizado na área de ciência da computação. Um exemplo da utilização desse modelo na área de negócios é apresentado por Andrade et al. (2004). Na Figura 3, a circunferência cheia se refere ao início das atividades, a circunferência vazia preenchida por outra cheia corresponde ao término das atividades, e o losango indica momento de decisão.

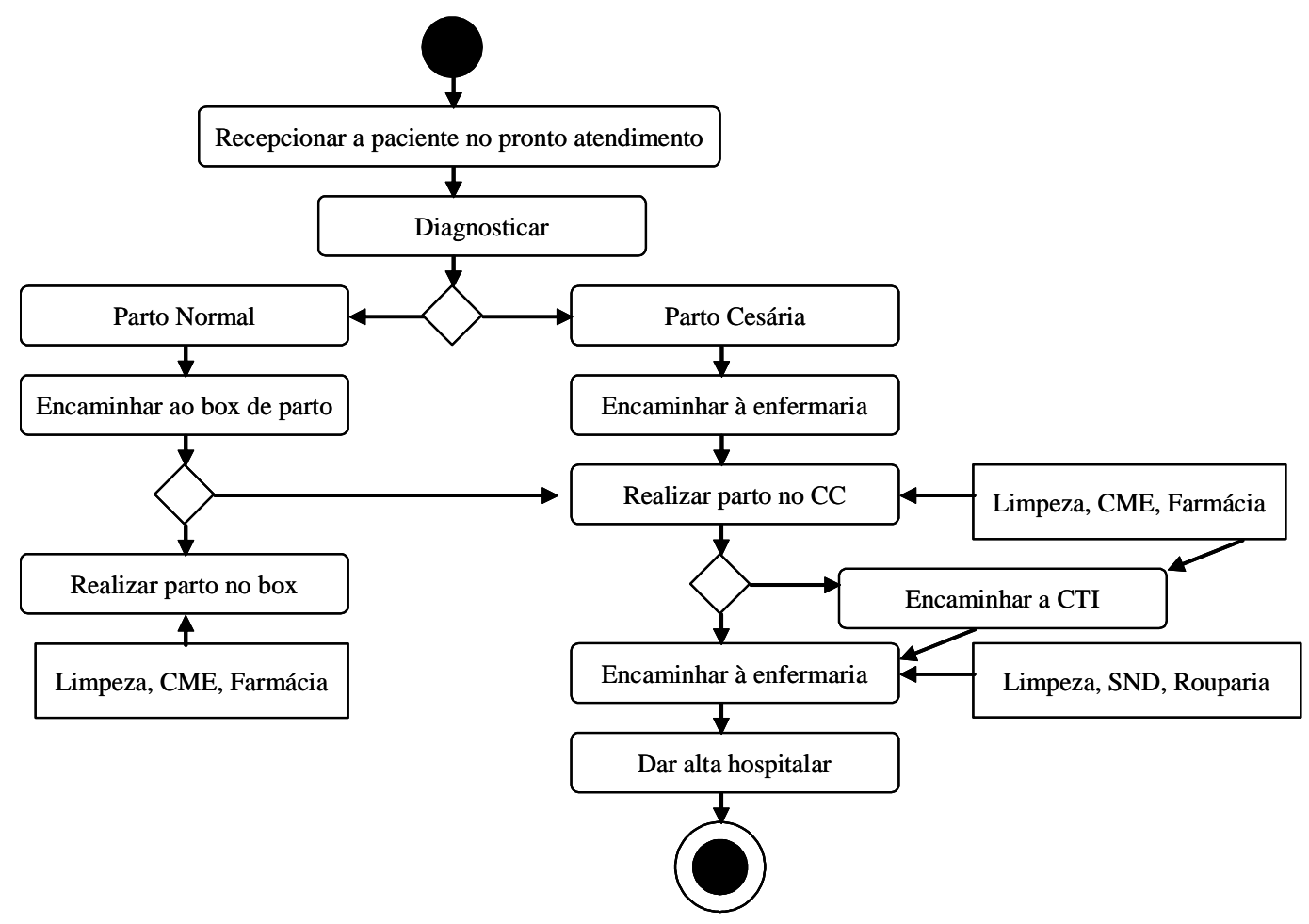

Figura 3. Diagrama de Atividades para os Procedimentos de Parto no Hospital I Fonte: Elaborado pelos autores.

Ao analisar esse diagrama (Figura 3), observa-se como ocorre o fluxo das atividades no bloco obstétrico do Hospital I. Essas atividades dão origem a registros que alimentarão o banco de dados do SIH. Esses dados, quando processados, devem gerar os diversos relatórios utilizados pelos gestores da organização hospitalar, tais como: faturamento, controle de tempo, controle de consumo de materiais médicos e medicamentos, custo do procedimento, entre outros. Em cada retângulo do diagrama 
Modelagem das atividades em centro cirúrgico de hospitais para o desenvolvimento de um sistema de informação hospitalar Antonio Artur de Souza, Mariana Guerra, Thaisy Las-Casas Amorin, Cynthia Oliveira Lara, Simone Letícia Raimundini

apresentam-se as atividades e os setores de apoio envolvidos (i.g., farmácia, limpeza, médicos, enfermeiras), que são identificados nos procedimentos de parto.

De forma geral, para realizar as cirurgias nos blocos cirúrgico e obstétrico do Hospital I, permanecem, no mínimo, um médico, um auxiliar (acadêmico de medicina), um técnico de enfermagem e um médico anestesiologista. Cabe à técnica de enfermagem elaborar a documentação da equipe da cirurgia no prontuário do paciente. O tempo das cirurgias não é sistematicamente anotado, mas se estima uma média de 60 minutos para o parto cesárea e de 70 minutos para a modalidade cesárea com laqueadura de trompas. Entretanto, a duração da cirurgia depende de cada médico responsável, sendo o tempo das demais cirurgias, em média, de 20 minutos para a laqueadura de trompa, 10 minutos para a vasectomia e 30 minutos para a cirurgia de varizes. Não existe planejamento para se evitar desperdício com o tempo ocioso no bloco.

O registro dos materiais utilizados na cirurgia é feito por meio da "folha de sala", porém não se especifica tudo o que é gasto. Isso ocorre porque o Hospital I presta serviços ao Sistema Único de Saúde (SUS) e recebe por procedimento. Dessa forma, mesmo que ocorram maiores gastos de materiais em um determinado parto, o valor repassado pelo SUS ao hospital por este procedimento é sempre o mesmo, ou seja, é tabelado como tipos de procedimentos padrões. Sendo assim, o compromisso da equipe médica com a qualidade do atendimento e o restabelecimento da saúde do paciente se sobrepõe a questão de gastos extras pela utilização de maior quantidade de material. Tal fato pode justificar a ausência de especificação completa e detalhada dos recursos utilizados em cada procedimento cirúrgico. Por sua vez, isso traz dificuldades de se estabelecer os reais custos envolvidos em cada cirurgia.

Os setores de apoio que prestam serviços ao CC são Almoxarifado, Farmácia, Central de Materiais Esterilizados (CME), Limpeza, Manutenção e Serviço de Nutrição e Dietética (SND), os quais estão sempre disponíveis para prestação de serviços aos blocos. O serviço de Limpeza é disponibilizado 24 horas por dia, realizado por duas funcionárias exclusivas para os blocos, e o tempo de limpeza e preparo da sala entre as cirurgias demanda, em média, 15 minutos. As funcionárias do SND levam a refeição ao 
Modelagem das atividades em centro cirúrgico de hospitais para o desenvolvimento de um sistema de informação hospitalar Antonio Artur de Souza, Mariana Guerra, Thaisy Las-Casas Amorin, Cynthia Oliveira Lara, Simone Letícia Raimundini

quarto das pacientes que não podem se locomover, contudo, incentiva-se as demais pacientes irem ao refeitório.

Quanto ao fluxo da rouparia, os funcionários do setor passam nos quartos após cada cirurgia, recolhem as roupas usadas e levam-nas para a lavanderia, que pertence ao próprio Hospital. No fluxo da CME, a técnica de enfermagem leva o material para a esterilização nessa Central. Os medicamentos a serem utilizados pelas pacientes ficam no estoque do CC, não havendo necessidade de as enfermeiras deslocarem-se até a Farmácia.

Essa descrição dos setores envolvidos no processo de prestação de serviços pelo CC é importante, uma vez que na modelagem das atividades devem-se considerar vários itens que serão controlados e monitorados pelo SI a ser desenvolvido. Assim, por meio dessa descrição e da análise do fluxograma apresentado (Figura 3), é possível definir as atividades comumente realizadas nos procedimentos de parto, ou seja, um modelo. A partir disso, é possível desenvolver um SIH específico para essa organização, uma vez que a modelagem possibilita compreender a seqüência de atividades e como essas ocorrem em função de um agente (i.e., a paciente) que está submetida ao procedimento cirúrgico.

\subsection{Hospital II}

O Hospital II é um hospital particular que presta serviços especialmente em ginecologia, cirurgia geral, urologia e ortopedia. O CC divide-se em bloco cirúrgico e bloco obstétrico, cada qual com farmácia própria. Das onze salas do CC, seis são específicas do bloco cirúrgico e cinco do bloco obstétrico. $O$ atendimento do bloco cirúrgico ocorre de segunda a sábado, das 07h00min às 22h00min, período de maior fluxo, embora existam condições de funcionamento ininterrupto.

No bloco obstétrico, o atendimento é realizado 24 horas por dia. Em casos específicos, algumas salas desse bloco podem ser utilizadas para outras cirurgias de pacientes do sexo feminino, exclusivamente. A demanda de atendimento atual do Hospital II é de, aproximadamente, novecentos procedimentos/mês, com uma média diária de quarenta cirurgias. Contudo, há registros de setenta cirurgias/dia para 
Modelagem das atividades em centro cirúrgico de hospitais para o desenvolvimento de um sistema de informação hospitalar Antonio Artur de Souza, Mariana Guerra, Thaisy Las-Casas Amorin, Cynthia Oliveira Lara, Simone Letícia

determinados períodos do ano. As cirurgias são marcadas via SI utilizado, agendadas de acordo com a necessidade da vaga e a disponibilidade das salas.

Não existe um funcionário com responsabilidade específica para o agendamento das cirurgias, e os próprios médicos podem realizá-lo via SI. Quando ocorrem alterações nos agendamentos em que a sala da cirurgia fica ociosa, apesar de gerar um custo extra para o Hospital, não é cobrada multa do paciente ou do médico. Dessa forma, o Hospital II assume os custos de manter a sala cirúrgica fechada, caso não consiga alocar outro médico para realizar a cirurgia naquele horário ocioso.

Todas as salas do CC possuem equipamentos próprios para a realização dos procedimentos cirúrgicos. O tempo gasto com a limpeza das salas oscila de 15 a 30 minutos conforme a atividade executada. Já o tempo de cirurgia varia de acordo com o cirurgião que a realiza e com a complexidade da mesma. Esse tempo é controlado e disponibilizado no banco de dados do SI do Hospital II. Com esses dados, é elaborado um relatório que objetiva evitar o desperdício de recursos, em que são apresentados os indicadores de ocupação das salas, tempo de atraso da cirurgia e suas possíveis causas (p.e., imprevistos, complicações, atrasos), dentre outras informações. O registro de materiais utilizados na cirurgia se dá por códigos de barras. O Hospital II trabalha com kits que ao serem dispensados pela Farmácia são registrados via SI na conta do paciente. Os outros materiais que por ventura não estiverem nos kits e que o cirurgião possa necessitar durante a cirurgia podem ser requisitados por prescrição eletrônica. Ao final do procedimento é gerada uma lista de materiais e medicamentos utilizados, a qual é assinada pelo cirurgião, médico anestesiologista e enfermeiros envolvidos.

Os procedimentos que antecedem a cirurgia são especificados pelo agendamento e pela consulta pré-anestésica para verificar a necessidade da utilização de algum material específico na cirurgia. No dia marcado para realização da cirurgia, após a chegada do paciente ao Hospital, é formalizada sua internação. Posteriormente, ele segue para o leito ou para a sala de espera, de onde é transportado para o CC. O paciente é assistido pela equipe médica na anestesia, no trânsito operatório e no pósoperatório. Do pós-operatório, o paciente pode seguir para a unidade de internação, 
para a Unidade de Tratamento Intensivo (UTI), ou para outro hospital, de acordo com o caso.

O relacionamento do CC com os setores de apoio ocorre de forma bastante coordenada. O setor de internação fornece um prontuário completo e etiquetado ao paciente internado no CC. A CME realiza a limpeza dos instrumentais e a Farmácia fornece os medicamentos e os materiais necessários. O setor de Limpeza realiza a higienização das salas. O Transporte, que integra o CC, presta serviços em todos os andares e realiza as atividades de locomoção de pacientes. O setor de Manutenção realiza a manutenção corretiva e preventiva dos equipamentos. O setor de Compras fornece o material instrumental e os equipamentos necessários nos procedimentos. A unidade de internação é o local onde os pacientes ficam internados e, quando ocorrem complicações com os pacientes do CC, a unidade é responsável por encaminhá-los para a internação na UTI e o retorno à unidade de internação. Tendo por base a descrição das atividades de cada setor do Hospital II, elaborou-se a Figura 4, em que se apresenta o diagrama de atividades dos procedimentos realizados no CC. 
Modelagem das atividades em centro cirúrgico de hospitais para o desenvolvimento de um sistema de informação hospitalar Antonio Artur de Souza, Mariana Guerra, Thaisy Las-Casas Amorin, Cynthia Oliveira Lara, Simone Letícia Raimundini

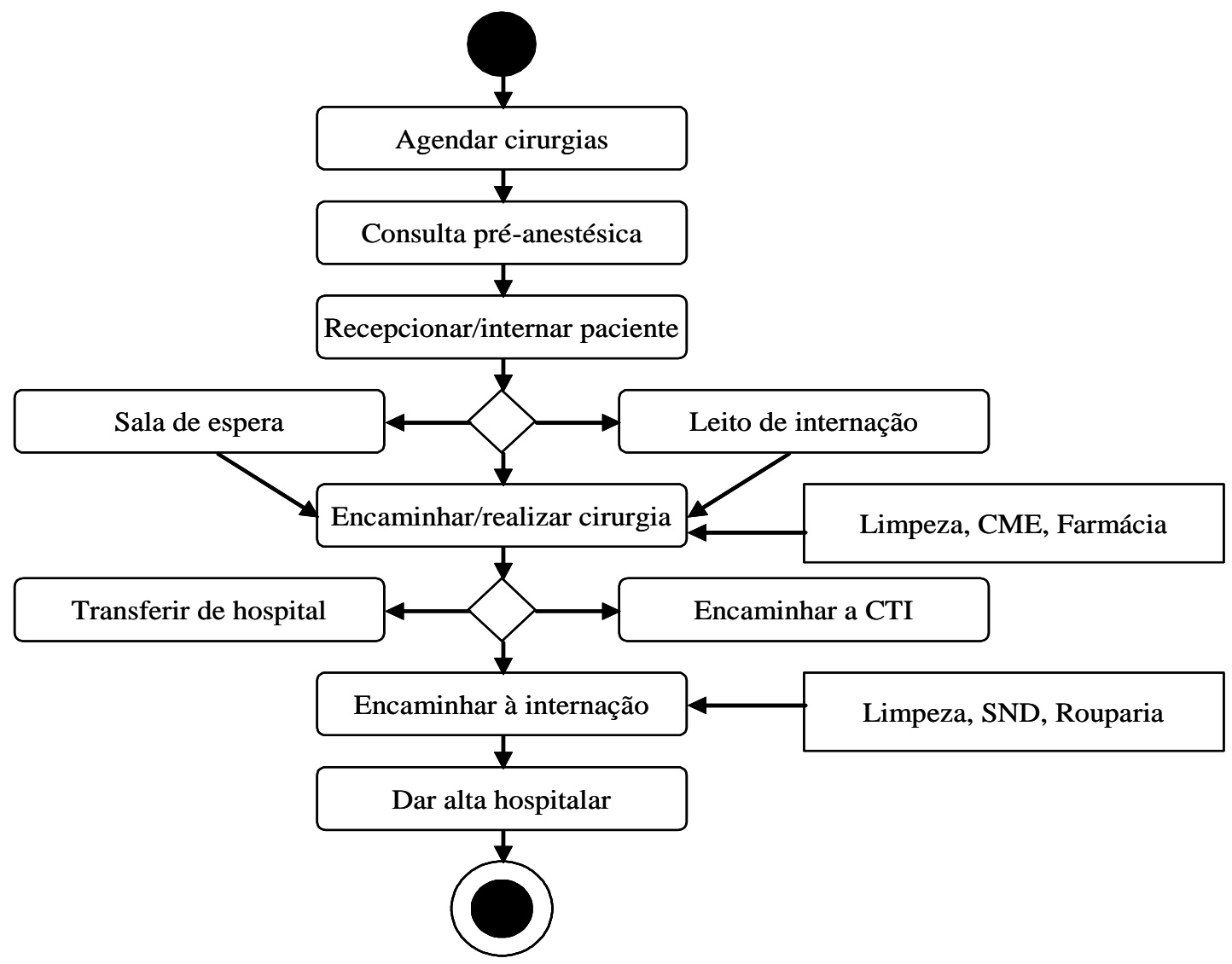

Figura 4. Diagrama de Atividades para os Procedimentos Cirúrgicos e Obstétricos no Hospital II Fonte: Elaborado pelos autores.

Examinando-se a figura 4, é possível compreender o início (circunferência cheia) e o término da prestação do serviço cirúrgico ou obstétrico (a circunferência vazia preenchida por outra cheia), desde o momento em que se faz o agendamento da cirurgia até a liberação do paciente. Os momentos de decisão (losangos) nesse procedimento são importantes, porque indicam o fluxo que o paciente seguirá, determinando os recursos que serão utilizados. Dessa forma, em um SIH integrado, após a descrição das atividades, é possível compreender a decorrência dos custos de cada procedimento e como esses se acumulam. Portanto, observa-se que para disponibilizar informações para a tomada de decisões em hospitais, o sistema utilizado deve capturar os dados de cada procedimento e apresentá-los de forma integrada.

O SIH utilizado no Hospital II possibilita uma comunicação entre todos os setores, viabilizando um controle de requisição e de utilização de materiais por 
Modelagem das atividades em centro cirúrgico de hospitais para o desenvolvimento de um sistema de informação hospitalar Antonio Artur de Souza, Mariana Guerra, Thaisy Las-Casas Amorin, Cynthia Oliveira Lara, Simone Letícia

procedimentos realizados. A CME, setor que mantém maior contato com o CC pode, por exemplo, verificar no SI o número de cirurgias que estão agendadas e, assim, preparar os materiais necessários.

\subsection{Hospital III}

O Hospital III é um hospital privado e o CC dessa organização consiste em três salas cirúrgicas, uma sala para pequenos procedimentos e oito apartamentos para internação. Normalmente, as atividades do CC são realizadas das $07 \mathrm{~h} 00 \mathrm{~min}$ às 17h00min, entretanto, de acordo com a demanda por intervenções cirúrgicas, o funcionamento pode se estender até as $22 \mathrm{~h} 00 \mathrm{~min}$. Realizam-se, em média, de seis a sete cirurgias por dia, sobretudo em decorrência da limitação do número de salas. A maximização do número de cirurgias ocorre quando alguns pacientes, de acordo com a cirurgia que foi realizada, são liberados logo após o procedimento.

No CC há cinco enfermeiras no quadro de pessoal permanente. O corpo clínico que compõe as equipes cirúrgicas no Hospital não possui vínculo com a organização, ou seja, é o chamado corpo clínico aberto. Desse modo, as cirurgias são marcadas pelo consultório do médico diretamente com a recepção. Esse agendamento é realizado de forma a atender à disponibilidade do Hospital em fornecer o espaço e à disponibilidade de data e horário do médico e de seu paciente para realizarem o procedimento. Além disso, a complexidade do procedimento cirúrgico é considerada para a escolha da sala, uma vez que essas possuem diferentes estruturas e equipamentos.

A respeito desses procedimentos, aproximadamente 24 horas antes da realização da cirurgia, a recepção entra em contato com o paciente para a confirmação do procedimento e para disponibilizar informações adicionais sobre a cirurgia. A recepção informa, durante esse contato, a necessidade ou não de preparo específico para o tipo de cirurgia. Dessa forma, as cirurgias realizadas normalmente não são emergenciais. Em caso de remarcação ou cancelamento, o Hospital III assume os custos de manter a sala cirúrgica fechada, caso não consiga agendar outra cirurgia naquele horário. Não se cobra multa do médico ao fazer o cancelamento da cirurgia; 
Modelagem das atividades em centro cirúrgico de hospitais para o desenvolvimento de um sistema de informação hospitalar Antonio Artur de Souza, Mariana Guerra, Thaisy Las-Casas Amorin, Cynthia Oliveira Lara, Simone Letícia Raimundini

porém, se o fato acontecer várias vezes, há possibilidade de o contrato entre o médico e o Hospital ser revisto.

Como forma de maximizar o número de cirurgias e evitar a ineficiência de tempo e do espaço utilizado, as salas do CC são preparadas no dia anterior à cirurgia, sempre de acordo com a agenda da manhã do dia seguinte. Quando a rotina não é modificada por alguma eventualidade, o paciente, ao chegar ao Hospital pela manhã, é logo submetido à aplicação de soro.

O serviço de limpeza é terceirizado e atua em todos os setores da organização. A partir do momento em que o médico anestesiologista libera o paciente do $\mathrm{CC}$, dá-se início a higienização da sala para uma nova cirurgia, o que demanda, em média, 30 minutos. Ademais, de acordo com a agenda, a Farmácia prepara um novo kit para a próxima cirurgia e protocola a listagem de medicamentos e materiais utilizados em sua montagem. Junto ao CC, há uma Farmácia de Apoio, que, além de montar os kits de cirurgia, solicita à CME determinados tipos de materiais que não se encontram no kit padrão. Nesse caso, a enfermagem anota na folha de controle do paciente os materiais extras, e a funcionária auxiliar de Farmácia anota em uma planilha para conferência futura. Na ausência dessa última funcionária, uma enfermeira responsabiliza-se por entrar e recolher o material necessário e manter esse controle.

A CME, que também presta serviços de apoio direto ao $\mathrm{CC}$, localiza-se no subsolo do Hospital, onde são esterilizados os instrumentais. Campos, capotes, compressas e outros materiais, como fio cirúrgico, são esterilizados por uma empresa terceirizada. A Figura 5 apresenta as atividades que ocorrem desde o agendamento até a alta do paciente no Hospital III. 
Modelagem das atividades em centro cirúrgico de hospitais para o desenvolvimento de um sistema de informação hospitalar Antonio Artur de Souza, Mariana Guerra, Thaisy Las-Casas Amorin, Cynthia Oliveira Lara, Simone Letícia

Raimundini

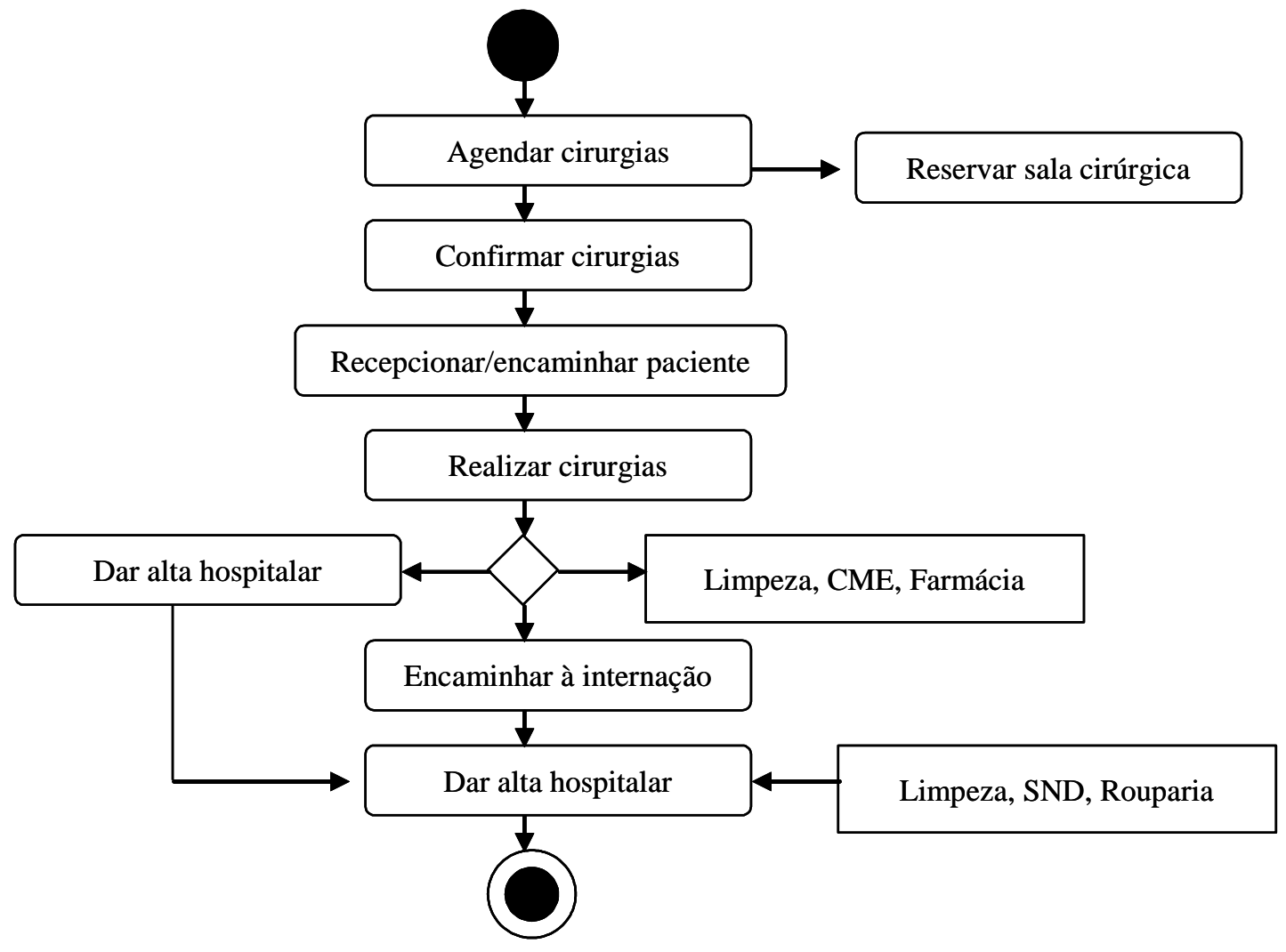

Figura 5. Diagrama de Atividades para Procedimentos Cirúrgicos Agendados no Hospital III Fonte: Elaborado pelos autores.

É importante observar que a complexidade dos procedimentos cirúrgicos, bem como a permanência ou não do paciente no Hospital III após a cirurgia, modifica o diagrama de atividades. Semelhante às demais figuras apresentadas, a circunferência cheia indica o início das atividades, a circunferência vazia preenchida por outra cheia indica o término das atividades, e o losango indica momento de decisão.

Apesar do planejamento realizado pela organização, inexiste um controle de duração de cada cirurgia realizada. São diversos tipos de procedimentos desenvolvidos e, como ocorre em vários hospitais, a única estimativa quanto à duração das cirurgias é por meio de anotação da hora de início e de término do procedimento, em folha de controle do CC (documento produzido pela enfermagem do Hospital III). As equipes que trabalham na sala de cirurgia geralmente são compostas por um médico, um auxiliar, um médico anestesiologista, um instrumentador e um circulante, havendo demanda 
Modelagem das atividades em centro cirúrgico de hospitais para o desenvolvimento de um sistema de informação hospitalar Antonio Artur de Souza, Mariana Guerra, Thaisy Las-Casas Amorin, Cynthia Oliveira Lara, Simone Letícia Raimundini

média de seis profissionais, que pode variar devido ao tipo de cirurgia. Existem procedimentos que podem precisar de até três médicos cirurgiões, como o caso de transplante capilar e algumas cirurgias ortopédicas.

O Hospital III é de pequeno porte e, apesar de utilizar um SI, esse não integra todos os setores da organização. Os dados do CC são disponibilizados no sistema pela enfermagem, mas alguns setores não possuem um controle informatizado, por exemplo, CME. Salienta-se que o Hospital dedica uma atenção relevante à satisfação das necessidades informacionais e operacionais dos médicos, já que os considera como um dos principais clientes da organização. Pode-se considerar que o hospital vende suas instalações para os médicos que, por sua vez, prestam serviços a seus pacientes utilizando-se dos recursos do hospital.

\subsection{Comparação entre os hospitais estudados}

Pelos dados apresentados, é possível observar que o Hospital II apresenta melhor qualidade das informações disponibilizadas pelo $\mathrm{SIH}$. Nessa organização, o SI utilizado possibilita uma comunicação entre todos os setores, o que viabiliza o controle de requisição e de utilização de materiais pelo CC. Por esse motivo, facilita-se a modelagem das atividades para a aplicação do sistema $A B C$ no $C C$ do Hospital II, uma vez que, por meio dos relatórios gerados pelo $\mathrm{SIH}$, é possível compreender a seqüência de atividades e a forma como essas ocorrem em função de um agente do CC (i.e., paciente). Além disso, no Hospital II, em decorrência da qualidade do SIH utilizado, torna-se possível controlar e analisar de forma sistematizada as decisões tomadas pelos gestores.

Nessa organização (Hospital II), por meio da análise dos momentos de decisão, é possível compreender a decorrência dos custos dos procedimentos e como esses se acumulam, e, assim, geri-los de forma mais eficaz e eficiente. Salienta-se, ainda, a automatização no processo de agendamento das cirurgias. Esse Hospital também utiliza um relatório de planejamento de materiais utilizados no $\mathrm{CC}$, evitando desperdícios. Ao término dos procedimentos, é gerada uma lista de materiais e de 
Modelagem das atividades em centro cirúrgico de hospitais para o desenvolvimento de um sistema de informação hospitalar Antonio Artur de Souza, Mariana Guerra, Thaisy Las-Casas Amorin, Cynthia Oliveira Lara, Simone Letícia Raimundini

medicamentos consumidos, que é assinada pela equipe médica, indicando o controle da utilização e do consumo de recursos, essencial para um sistema de custeio.

No Hospital I, diferentemente, não se realiza o controle de tempo das cirurgias realizadas. Além disso, não existe um planejamento para evitar desperdício com o tempo ocioso das salas do CC. O registro dos materiais utilizados nas cirurgias é realizado na "folha de sala", porém não se especificam todos os recursos consumidos. A despreocupação em fazer o controle de materiais médicos pode ser justificada pelo fato de o Hospital I prestar serviços aos SUS e receber remuneração por procedimento padrão. Esta falta de controle prejudica a especificação dos custos por cirurgia, o que é essencial para o custeamento do procedimento e para a avaliação da margem de lucro do serviço prestado.

Ademais, por meio dos dados apresentados, é possível observar que as atividades desenvolvidas no $\mathrm{CC}$ do Hospital I são semelhantes às atividades desse mesmo setor do Hospital II. Apesar de não haver controle e planejamento via SIH dos procedimentos desenvolvidos no CC do Hospital I, é possível compreender o início e o término do procedimento cirúrgico ou obstétrico, desde o momento em que se faz o agendamento da cirurgia até a liberação do paciente. Isso pode ser observado pelo diagrama de atividades (Figura 3 ). Dessa forma, a modelagem das atividades para desenvolvimento de um SIH que possibilite a utilização do sistema ABC no Hospital II pode ser utilizada, também, para aplicação no Hospital I.

Por fim, no Hospital III, apesar de ser utilizado um SIH, esse não integra todos os setores da organização. Os dados do CC são disponibilizados no sistema pela Enfermagem, mas alguns setores não são abrangidos por um controle informatizado (p.e., CME). Os procedimentos de apoio ao CC são controlados por meio de fichas ou folhas de controle, e a auxiliar de Farmácia anota os dados do procedimento em uma planilha para conferência futura. Apesar do Hospital III realizar um planejamento para utilização das salas de cirurgia, inexiste um controle pormenorizado da duração de cada procedimento.

Dessa forma, por meio dos dados apresentados, é possível observar que as atividades desenvolvidas no $\mathrm{CC}$ dos três Hospitais são semelhantes. Apesar de não 
Modelagem das atividades em centro cirúrgico de hospitais para o desenvolvimento de um sistema de informação hospitalar Antonio Artur de Souza, Mariana Guerra, Thaisy Las-Casas Amorin, Cynthia Oliveira Lara, Simone Letícia

haver controle e planejamento via SIH dos procedimentos desenvolvidos no CC dos Hospitais I e III, por meio da análise do diagrama de atividades dessas organizações é possível compreender as etapas realizadas para o desenvolvimento dos procedimentos do CC, assim como os setores de apoio envolvidos. Nota-se que para o desenvolvimento de um SIH nestas organizações, há a necessidade de implantar, primeiramente, controles internos relativos a custos, principalmente nos Hospitais I e III.

Como mencionado, os momentos de decisão nesses procedimentos são importantes, uma vez que indicam o fluxo a ser seguido pelo paciente no $C C$, determinando os recursos necessários para o atendimento do cliente. Dessa forma, a modelagem das atividades para a possível implantação do sistema $A B C$ converge aos três Hospitais pesquisados, apesar de algumas diferenças entre os procedimentos realizados nos CC estudados.

Portanto, a fim de modelar as atividades de forma comum para os três Hospitais, bem como identificar os demais itens que serão relacionados no SIH para possibilitar a implantação do $A B C$, algumas etapas devem ser cumpridas, tais como:

- Listagem dos recursos consumidos;

- Listagem das atividades realizadas;

- Definição dos direcionadores de recursos;

- Mapeamento dos recursos por atividades;

- Listagem dos serviços prestados, tendo-se como base os direcionadores;

- Definição dos direcionadores de custos (atividades);

- Mapeamento das atividades por serviços com base nos direcionadores.

Essas etapas foram realizadas a partir das informações obtidas nos estudos de caso desses três Hospitais. Nos Quadros 1 a 7 são agrupados os resultados da pesquisa com base no desenvolvimento das sete etapas que podem possibilitar a implantação do sistema $A B C$, dada a modelagem das atividades.

Especificamente, a partir da aplicação dessas etapas, chega-se a um mapeamento das atividades desenvolvidas nesse setor, ou seja, após a listagem das atividades e dos recursos consumidos, estabeleceram-se os direcionadores de recursos. De forma análoga, estabeleceram-se os serviços e as atividades que se 
Modelagem das atividades em centro cirúrgico de hospitais para o desenvolvimento de um sistema de informação hospitalar Antonio Artur de Souza, Mariana Guerra, Thaisy Las-Casas Amorin, Cynthia Oliveira Lara, Simone Letícia Raimundini

relacionam aos serviços prestados, obtendo-se os direcionadores de custos (ou direcionadores de atividades) adequados para cada atividade elencada.

Neste estudo iniciou-se a determinação dos recursos consumidos no CC que se encontram listados no Quadro 1. Dentre tais recursos, tem-se o pessoal alocado, diversos tipos de materiais de consumo e até mesmo os materiais recebidos de outros setores de apoio.

\begin{tabular}{|c|c|}
\hline Código & Recursos \\
\hline R01 & Pessoal \\
\hline R02 & Material de consumo \\
\hline R03 & Material médico-hospitalar \\
\hline R04 & Energia Elétrica \\
\hline R05 & Telefone \\
\hline R06 & Água e esgoto \\
\hline \multirow{4}{*}{ R07 } & Recebidos de outros setores \\
\cline { 2 - 2 } & Almoxarifado \\
\cline { 2 - 2 } & Manutenção \\
\cline { 2 - 2 } & Pessoal \\
\cline { 2 - 2 } & SND \\
\cline { 2 - 2 } & Lavanderia \\
\cline { 2 - 2 } & CME \\
\cline { 2 - 2 } & Farmácia \\
\cline { 2 - 2 } & Limpeza \\
\hline
\end{tabular}

Quadro 1: Listagem dos recursos utilizados no centro cirúrgico Fonte: elaborado pelos autores.

Tal como descrito nas seções 6.1 a 6.3, observa-se que para a prestação dos serviços no $\mathrm{CC}$, há o envolvimento direto e indireto de outros setores das organizações, tais como: PA, Almoxarifado, Farmácia, CME, Limpeza, Manutenção e SND. Destacase que para facilitar o entendimento dos recursos consumidos para a prestação dos serviços, utilizaram-se as nomenclaturas: (i) pessoal - que se refere a funcionários diversos envolvido no processo; (ii) material de consumo - recursos diversos e não específicos utilizados (p.e., luvas, roupas de cama, algodão, gases); (iii) material 
Modelagem das atividades em centro cirúrgico de hospitais para o desenvolvimento de um sistema de informação hospitalar Antonio Artur de Souza, Mariana Guerra, Thaisy Las-Casas Amorin, Cynthia Oliveira Lara, Simone Letícia Raimundini

médico-hospitalar - referentes aos recursos específicos, tais como remédios, anestesias ou outros medicamentos, bem como agulhas, seringas, bisturis.

Em seguida, listaram-se as atividades desenvolvidas para a prestação dos serviços (Quadro 2). Essas atividades basearam-se nos fluxogramas apresentados nas seções 6.1 a 6.3 .

\begin{tabular}{|c|c|c|}
\hline Código & Atividades & Descrição das Atividades \\
\hline A1 & Admitir paciente & $\begin{array}{c}\text { Recepcionar o paciente munido do prontuário da unidade de } \\
\text { origem. Verificar a preparação pré-operatória do paciente e } \\
\text { orientá-lo quanto a troca de roupa, conferir e confirmar a } \\
\text { cirurgia. }\end{array}$ \\
\hline $\mathrm{A} 2$ & $\begin{array}{l}\text { Preparar sala de } \\
\text { cirurgia }\end{array}$ & $\begin{array}{l}\text { (a) colocar na sala todos os pacotes estéreis, caixas de } \\
\text { instrumental, material e medicamentos que serão utilizados; } \\
\text { (b) arrumar o instrumental e o material necessários à } \\
\text { cirurgia; (c) arrumar o material de anestesia; (d) conferir o } \\
\text { foco (iluminação) e montar os aspiradores; }\end{array}$ \\
\hline A3 & Anestesiar paciente & $\begin{array}{c}\text { Aplicar a anestesia e acompanhar pacienta durante a } \\
\text { cirurgia; }\end{array}$ \\
\hline A4 & Realizar cirurgia & Realização do ato cirúrgico, conforme diagnóstico; \\
\hline A5 & Auxiliar equipe médica & $\begin{array}{l}\text { A equipe de enfermagem auxilia a equipe médica na } \\
\text { realização da cirurgia; }\end{array}$ \\
\hline A6 & $\begin{array}{l}\text { Preparar peças para } \\
\text { exames patológicos }\end{array}$ & $\begin{array}{l}\text { (a) colocar a peça no vasilhame com solução de formol a } \\
10 \% \text {; (b) rotular frasco; (c) preencher o formulário de } \\
\text { requisição de exame anatomopatológico; (d) entregar o } \\
\text { frasco com a requisição ao funcionário do laboratório; }\end{array}$ \\
\hline A7 & $\begin{array}{l}\text { Transferir paciente } \\
\text { para unidade de } \\
\text { internação }\end{array}$ & $\begin{array}{c}\text { (a) transferir paciente da mesa cirúrgica para maca; (b) } \\
\text { comunicar a equipe de enfermagem da unidade onde será } \\
\text { internado; (c) informar sobre o ato cirúrgico do paciente, } \\
\text { medicações e cuidados especiais e entregar o prontuário do } \\
\text { paciente; }\end{array}$ \\
\hline A8 & $\begin{array}{l}\text { Preparar sala após } \\
\text { cirurgia }\end{array}$ & $\begin{array}{l}\text { a) recolher instrumental utilizado, separando-se o material } \\
\text { cortante; (b) encaminhar instrumental e outros materiais } \\
\text { para esterilização; (c) recolher compressas, roupas e } \\
\text { campos no saco plástico e encaminhar para esterilização; } \\
\text { (d) guardar material e medicamentos não utilizados; (e) } \\
\text { encaminhar para a lavanderia pacotes esterilizados que } \\
\text { foram abertos; (f) organizar material permanente na sala; (g) } \\
\text { recolher lixo e proceder à desinfecção da sala. }\end{array}$ \\
\hline
\end{tabular}

Quadro 2: Descrição das atividades do Centro Cirúrgico Fonte: elaborado pelos autores.

Com base na listagem dos recursos e das atividades, podem-se estabelecer direcionadores de recursos (Quadro 3). Estes, uma vez definidos, conforme critérios de 
Modelagem das atividades em centro cirúrgico de hospitais para o desenvolvimento de um sistema de informação hospitalar Antonio Artur de Souza, Mariana Guerra, Thaisy Las-Casas Amorin, Cynthia Oliveira Lara, Simone Letícia Raimundini

adequação à mensuração do recurso, acessibilidade e facilidade de tabulação, são distribuídos em função das atividades em que tais recursos são consumidos.

\begin{tabular}{|c|c|c|}
\hline \multicolumn{3}{|c|}{ Direcionadores de recursos } \\
\hline Código & Nome & Recursos relacionados (código) \\
\hline DR01 & Tempo em minutos & R01 a R07 \\
\hline DR02 & Kwh & R04 \\
\hline DR03 & Estimativa gerencial & R02, R03 e R06 \\
\hline DR04 & Alocação direta & R05 \\
\hline
\end{tabular}

Quadro 3: Listagem dos direcionadores de recursos no centro cirúrgico Fonte: elaborado pelos autores.

O recurso telefone (R05) pode ser identificado separadamente de acordo com as atividades desenvolvidas. Os recursos R02, R03 e R06, por sua vez, poderão ser alocados às atividades por meio de estimativa gerencial. A energia elétrica consumida nas atividades poderá ser alocada por meio do direcionador DR02 (Kwh). Para alocação dos recursos R01 a R07, pode ser utilizado também o direcionador tempo em minutos.

Após essa identificação, é possível alocar os recursos às atividades por meio dos direcionadores de recursos, distribuindo-os entre as atividades desempenhadas no setor (Quadro 4).

\begin{tabular}{|c|c|c|}
\hline Recursos & Direcionadores de recursos & Atividades \\
\hline R01 & Tempo em minutos & A1 a A8. \\
\hline R02 & Tempo em minutos e Estimativa gerencial & A2, A4, A6 e A8 \\
\hline R03 & Tempo em minutos e Estimativa gerencial & A3 e A4 \\
\hline R04 & Tempo em minutos e Kwh & A4, A6 e A8 \\
\hline R06 & Tempo em minutos e Estimativa gerencial & A8 \\
\hline R07 & Tempo em minutos & A1 a A8 \\
\hline
\end{tabular}

Quadro 4: Atribuição dos direcionadores de recursos para as atividades desempenhadas no centro cirúrgico

Fonte: elaborado pelos autores. 
Modelagem das atividades em centro cirúrgico de hospitais para o desenvolvimento de um sistema de informação hospitalar Antonio Artur de Souza, Mariana Guerra, Thaisy Las-Casas Amorin, Cynthia Oliveira Lara, Simone Letícia

Raimundini

\begin{tabular}{|c|c|}
\hline Código & Serviços \\
\hline S01 & Cardiologia \\
\hline S02 & Neurologia \\
\hline S03 & Ortopedia \\
\hline S04 & Ginecologia \\
\hline S05 & Urologia \\
\hline S06 & Proctologia \\
\hline S07 & Plástica \\
\hline S08 & Diversas \\
\hline
\end{tabular}

Quadro 5: Descrição dos serviços do centro cirúrgico Fonte: elaborado pelos autores.

No caso do CC, a listagem dos serviços realizados é bastante extensa, afinal inúmeros tipos de cirurgias são realizados rotineiramente. Sendo assim, neste estudo optou-se por diferenciar os serviços realizados no CC pela área clínica com a qual se relaciona o tipo de cirurgia. Dessa forma, os serviços do CC foram listados em 8 modalidades conforme Quadro 5.

A partir da identificação e compreensão das atividades desempenhadas e dos indicadores ou objetos aos quais estas se relacionam, estabelecem-se os direcionadores de custos, também denominados direcionadores de atividades (Quadro 6). Uma vez estabelecidos os direcionadores de custos, relacionam-se, por meio destes, as atividades desempenhadas a cada um dos serviços, neste caso, cirurgias divididas pelas respectivas áreas clínicas, conforme consta no Quadro 7.

\begin{tabular}{|c|c|c|}
\hline \multicolumn{2}{|c|}{ Direcionadores de custos (atividades) } \\
\hline Código & Nome & Atividades relacionadas \\
\hline DC1 & № de pacientes & A02, A07e A08 \\
\hline DC2 & № de aplicações de anestesia & A03 \\
\hline DC3 & $\begin{array}{c}\text { Tempo despendido na } \\
\text { atividade }\end{array}$ & A03, A04, A05 e A06 \\
\hline
\end{tabular}

Quadro 6: Atribuição dos direcionadores de custos no centro cirúrgico Fonte: elaborado pelos autores.

Dessa forma, a partir da modelagem das atividades do CC, desenvolvida por meio dessas sete etapas, pode se estabelecer bases para a elaboração de um SI que atenda a demanda das atividades desenvolvidas neste setor hospitalar. Entretanto, 
Modelagem das atividades em centro cirúrgico de hospitais para o desenvolvimento de um sistema de informação hospitalar Antonio Artur de Souza, Mariana Guerra, Thaisy Las-Casas Amorin, Cynthia Oliveira Lara, Simone Letícia

Raimundini

outros passos devem ser contemplados a fim de que os custos envolvidos nos serviços sejam alocados por meio da utilização dos direcionadores de custos estabelecidos.

\begin{tabular}{|c|c|c|}
\hline Atividades & Direcionadores de custos (atividades) & Serviços \\
\hline $\bar{A} 1$ & № de pacientes & S01 a S08 \\
\hline A2 & № de pacientes & S01 a S08 \\
\hline A3 & № de aplicações de anestesia, Tempo despendido na atividade & S01 a S08 \\
\hline A4 & Tempo despendido na atividade & S01 a S08 \\
\hline A5 & $\begin{array}{l}\text { Número de horas despendidas no controle, Tempo despendido na } \\
\text { atividade }\end{array}$ & S01 a S08 \\
\hline A6 & Tempo despendido na atividade & $\begin{array}{l}\text { S01 a S06 e } \\
\text { S08 }\end{array}$ \\
\hline A7 & № de pacientes & S01 a S08 \\
\hline A8 & № de pacientes & S01 a S08 \\
\hline
\end{tabular}

Quadro 7: Atividades geralmente desenvolvidas em cada serviço prestado pelo centro cirúrgico Fonte: elaborado pelos autores

Assim, as próximas etapas da pesquisa deverão determinar o custo de realização de cada atividade; selecionar direcionadores de custos para cada atividade; determinar o volume dos direcionadores de custo disponíveis de acordo com os recursos destinados àquela atividade; calcular a taxa dos direcionadores de custo da atividade e atribuir os custos aos objetos de custos com base na taxa de direcionador de custo.

\section{CONCLUSÃO}

Os resultados deste estudo possibilitam concluir que a modelagem das atividades do $\mathrm{CC}$ dos Hospitais I, II e III apresenta as principais informações necessárias para o desenvolvimento de SIH para organizações hospitalares, que possibilitam a implantação do sistema $\mathrm{ABC}$. Algumas melhorias no modelo apresentado são necessárias, mas não inviabilizam a sua utilização. Além disso, para o desenvolvimento do SIH que possibilite a implantação do $A B C$, são necessárias algumas mudanças, tais como: investimento para a melhoria do SIH utilizado no Hospital III, a fim de que esse SI contemple o modelo apresentado e possibilite a implantação do $\mathrm{ABC}$; desenvolvimento e informatização dos mecanismos de controle 
Modelagem das atividades em centro cirúrgico de hospitais para o desenvolvimento de um sistema de informação hospitalar Antonio Artur de Souza, Mariana Guerra, Thaisy Las-Casas Amorin, Cynthia Oliveira Lara, Simone Letícia Raimundini

utilizados nos Hospitais I e III; melhoria da infra-estrutura em equipamentos de informática nos três Hospitais; capacitação técnica dos funcionários responsáveis pela tomada de decisão; e desenvolvimento da cultura organizacional a fim de facilitar a implantação do sistema ABC.

Dessa forma, o objetivo principal desse estudo foi modelar as atividades do CC de hospitais, a fim de se desenvolver, futuramente, o $\mathrm{SIH}$, especificamente para a implantação do sistema ABC. Assim, foi possível desenvolver uma modelagem das atividades do $\mathrm{CC}$ dos hospitais pesquisados, por meio dos diagramas apresentados nas seções 6.1 a 6.3. Ao se comparar a modelagem das atividades dos três hospitais, pôdese concluir que é possível desenvolver SIH abrangente para implantação do sistema $A B C$ que atenda aos procedimentos fundamentais dos $C C$ estudados, quais sejam: recepcionar paciente, encaminhar paciente, realizar cirurgia, encaminhar paciente para internamento e/ou alta hospitalar, limpar as salas do CC, e preparar materiais e medicamentos para a próxima cirurgia agendada. A complexidade ou simplicidade dos procedimentos realizados, que influencia a implantação do sistema $A B C$ e da modelagem das atividades, depende da estrutura organizacional do hospital e dos tipos de cirurgia que são realizadas.

Sabe-se que o processo de modelagem de atividades, realizado com o intuito de se desenvolver um SIH para a implantação do sistema $A B C$, constitui-se em uma tarefa que exige a habilidade de compilação e sistematização de dados de uma realidade complexa e dinâmica. Assim, os usuários da modelagem de atividades, sejam profissionais da área de informática ou da área administrativa-operacional, conseguem compreender com mais facilidade o fluxo de recursos e de informações entre as diversas atividades necessárias para a consecução dos objetivos operacionais. Essa modelagem deve ser considerada para a compreensão dos procedimentos e do desenvolvimento do $\mathrm{SIH}$.

A modelagem, por meio da utilização dos diagramas de atividades, possibilita uma visão sistêmica do processo de prestação do serviço no setor CC. Assim, podemse compreender os diversos aspectos para o desenvolvimento de um $\mathrm{SIH}$, quais sejam: (i) a necessidade de recursos para prestar o serviço; (ii) a causa e o efeito da atividade; 
Modelagem das atividades em centro cirúrgico de hospitais para o desenvolvimento de um sistema de informação hospitalar Antonio Artur de Souza, Mariana Guerra, Thaisy Las-Casas Amorin, Cynthia Oliveira Lara, Simone Letícia

(iii) como os dados são gerados; (iv) como e quando esses devem ser capturados pelo $\mathrm{SIH}, ;$ (v) quando a prestação do serviço não se apresenta de forma padrão e como isso interfere nos custos.

Embora seja um estudo inicial, espera-se que esta modelagem apresentada possa ser utilizada como parâmetro por outras organizações hospitalares que desejem adotar o sistema ABC e/ou desenvolver um SIH. Por fim, destaca-se que uma limitação deste estudo foi a ausência de controles internos dos Hospitais I e III, prejudicando o desenvolvimento da modelagem das atividades para o setor CC dessas organizações. A fim de que se completem as etapas para a efetiva implantação do $A B C$, informações específicas de custos se fazem necessárias. Dessa forma, as próximas etapas da pesquisa deverão determinar o volume dos direcionadores de custos disponíveis conforme os recursos destinados às atividades. $E$, posteriormente, estabelecer o cálculo da taxa dos direcionadores de custo da atividade, executando-se a atribuição dos custos aos objetos de custos com base na taxa dos direcionadores.

\section{REFERÊNCIAS}

ABBAS, K. (2001). Gestão de custos em organizações hospitalares. Florianópolis, SC. (Dissertação de Mestrado). Universidade Federal de Santa Catarina, UFSC, 155 p.

ALEMI, F.; SULLIVAN, T. (2007). An Example of Activity Based Costing of treatment programs. The American Journal of Drug and Alcohol Abuse, v. 33, n. 1, pp. 89-99.

ANDRADE, A.; RIBEIRO, A.; BORGES, E.; NEVES, W. (2004). Um estudo de aplicação de modelagem de processo de negócio para apoiar a especificação de requisitos de um sistema. In: VI Simpósio Internacional de Melhoria de Processos de Software. São Paulo. Disponível em: <http://www.simpros.com.br/Apresentacoes_PDF/Artigos/Art_16_Simpros-2004.pdf>. Acesso em: 21/mai/2008.

BARDIN, L. (1977). Análise de conteúdo. Lisboa: Edições 70.

BITTENCOURT, O. N. S. (1999). O emprego do método de custeio baseado em atividades - Activity-Based Costing (ABC) - como instrumento de apoio à decisão na área hospitalar. (Dissertação de Mestrado). Porto Alegre, RS. Escola de Administração, Universidade Federal do Rio Grande do Sul, EA/UFRGS, 198 p. 
Modelagem das atividades em centro cirúrgico de hospitais para o desenvolvimento de um sistema de informação hospitalar Antonio Artur de Souza, Mariana Guerra, Thaisy Las-Casas Amorin, Cynthia Oliveira Lara, Simone Letícia

BOTELHO, E. M. (2006). Custeio baseado em atividades - ABC: uma aplicação em uma organização hospitalar universitária. Ribeirão Preto, SP. (Tese de Doutorado). Faculdade de Economia, Administração e Contabilidade de Ribeirão Preto da Universidade de São Paulo, FEARP-USP, 340 p.

BOOCH, G.; RUMBAUGH, J.; JACOBSON, I. (2005). UML: guia do usuário. (2 ed.). Rio de Janeiro: Elsevier, $474 \mathrm{p}$.

BRIMSON, J. A. (1996). Contabilidade por atividades: uma abordagem de custeio baseado em atividades. São Paulo.

CARDINAELS, E.; ROODHOOFT, F.; VAN HERCK, G. (2004). Drivers of cost system development in hospitals: results of a survey. Health Policy, v. 69, n. 2, pp. 239-252.

CHING, H. Y. (1997). Gestão baseada em custeio por atividade. São Paulo: Atlas.

CULLINANE, K.; TOY, N. (2000). Identifying influential attributes in freight route/mode choice decisions: a content analysis. Transportation Research Part E: Logistics and Transportation Review, v. 36, n. 1, pp. 41-53.

DENZIN, N. K.; LINCOLN, Y. O. (2005). The Sage handbook of qualitative research. (3 ed.). London: Sage Publications, $1232 \mathrm{p}$.

EDEN, R.; LAY, C.; MAINGOT, M. (2006). Preliminary findings on ABC adoption in Canadian hospitals: reasons for law rates of adoption. The Irish Accounting Review, v. 13, n. 3, pp. 21-34.

FLICK, U. (2004). Uma introdução à pesquisa qualitativa. Porto Alegre: Bookman, 312 p.

FINKLER, S. A.; WARD, D. M. (1999). Essentials of cost accounting for health care organizations. (2 ed.). Maryland: Aspen Publication.

FURUIE, S. S. et al. (2007). Managing medical images and clinical information: InCor's experience. IEEE Transactions on Information Technology in Biomedicine, v. 11, n. 1, pp. 17-24.

GHELLERE, T.; ANTÔNIO, M. C.; SOUZA, M. L. (1993). Centro cirúrgico: aspectos fundamentais para enfermagem. Florianópolis: Editora UFSC, $182 \mathrm{p}$.

HANSEN, D. R.; MOWEN, M. M. (2006). Cost management: accounting and control. (5 ed.). Mason, Ohio: Thomson/South-Western, 2006, 1034 p. 
Modelagem das atividades em centro cirúrgico de hospitais para o desenvolvimento de um sistema de informação hospitalar Antonio Artur de Souza, Mariana Guerra, Thaisy Las-Casas Amorin, Cynthia Oliveira Lara, Simone Letícia

HORNGREN, C. T.; FOSTER, G.; DATAR, S. M. (2004). Contabilidade de custos. v. 1. (11 ed.). São Paulo: Pearson Prentice Hall, 526 p.

HU UFSC. Hospital Universitário da Universidade Federal de Santa Catarina. Disponível em: <http://www.hu.ufsc.br/ ccirurgico/folia1.htm>. Acesso em: 22/jul/2008.

LENZ, R.; KUHN, K.A. (2004). Towards a continuous evolution and adaptation of information systems in healthcare. International Journal of Medical Informatics, v. 73, n. 1 , pp. 75-89.

MALAGÓN-LONDOÑO, G.; MORERA, R. G.; LAVERDE, G. P. (2003). Administração hospitalar. (2 ed.). Buenos Aires: Editorial Médica Panamericana, 488 p.

McLEAN, R. A. (2003). Financial management in health care organizations. (2 ed.). Canada: Thomson Delmar Learning, $412 \mathrm{p}$.

NERI, E. L.; HOPPEN, N. (2003). Modelagem de um sistema multiagente para compras de suprimentos de TI usando Agent UML. In: XXVI Encontro da ANPAD, Atibaia. Anais...Atibaia: Anpad.

PIDD, M. (1998). Modelagem empresarial: ferramentas para tomada de decisão. Porto Alegre: Bookman, $318 \mathrm{p}$.

RAIMUNDINI, S. L. (2003). Aplicabilidade do sistema ABC e análise de custos: estudo de caso em hospitais públicos. Maringá, PR. (Dissertação de Mestrado). Universidade Estadual de Maringá - UEM, 200 p.

RUMBAUGH, J.; BLAHA, M.; PREMERIANI, W.; EDDY, F.; LORENSEN, W. (1994). Modelagem e projetos baseados em objeto com UML. (2 ed.). Rio de Janeiro: Campus, $576 \mathrm{p}$.

SILVA, M. D'A. A.; ROGRIGUES, A. L; CESARETTI, I. U. R. (1997). Enfermagem na Unidade de Centro Cirúrgico. (2 ed.). São Paulo: EPU, 252 p.

SOBECC. Sociedade Brasileira de Enfermeiros de Centro Cirúrgico, Recuperação Anestésica e Centro de Materiais Esterilizados. Disponível em: <http://www.sobecc.org.br/info.htm\#cme>. Acesso em: 22/jul/2008.

STRUETT, M. A. M. (2005). Custeio Baseado em Atividades em Laboratórios de Análises Clínicas: estudo de caso em um hospital filantrópico. Londrina, PR. (Dissertação de Mestrado). Universidade Estadual de Londrina - UEL, 165 p.

VAIVIO, J. (2008). Qualitative management accounting research: rationale, pitfalls and potential. Qualitative Researching Accounting \& Management, v. 5, n. 1, pp. 64-86. 
Modelagem das atividades em centro cirúrgico de hospitais para o desenvolvimento de um sistema de informação hospitalar Antonio Artur de Souza, Mariana Guerra, Thaisy Las-Casas Amorin, Cynthia Oliveira Lara, Simone Letícia Raimundini

UPDA, S. (1996). Activity-based costing for hospitals. Health Care Management Review, v. 21, n. 3, pp. 82-96.

YIN, R. K. (2005). Estudo de caso: planejamento e métodos. (3 ed.). Porto Alegre: Bookman, $212 \mathrm{p}$.

ZANOTELI, E. J. (2001). Avaliação de sistemas integrados de gestão: um estudo de caso múltiplo. 262p. (Dissertação de Mestrado). Universidade Federal de Minas Gerais, Belo Horizonte, 2001.

Data de Submissão: 17/11/2008

Data de Aceite: 10/09/2009 